\title{
KORELASI AKTIVITAS FISIK DENGAN KUALITAS TIDUR IBU HAMIL: STUDI CROSS SECTIONAL
}

\author{
Ahmad Khaerul Anam ${ }^{1}$, Raden Nety Rustikayanti ${ }^{2 *}$, Yeti Hernawati $^{\mathbf{3}}$ \\ ${ }^{1,2}$ Program Studi Sarjana Keperawatan, STIKes Dharma Husada Bandung \\ ${ }^{3}$ Program Studi Diploma Keperawatan, STIKes Dharma Husada Bandung \\ *)neroe_zul@yahoo.co,id
}

\begin{abstract}
Abstrak
Gangguan tidur yang buruk dapat mengakibatkan komplikasi kehamilan. Gangguan tidur dapat berbeda pada setiap pada setiap ibu hamil bergantung pada aktivitas fisik. Tujuan penelitian untuk mengetahui korelasi aktivitas fisik dengan kualitas tidur pada ibu hamil. Jenis penelitian korelasi dengan pendekatan cross sectional. Populasi penelitian sebanyak 248, dengan tehnik purposive sampling sebanyak 97 responden. Instrumen penelitian menggunakan kuesioner International Physical Activity Questionnaire (IPAQ) dan Pittsburgh Sleep Quality Index (PSQI). Analisis data menggunakan Chi Square. Hasil penelitian didapatkan nilai $\mathrm{p}$ sebesar $0.003(\mathrm{p}<\alpha)$. Disimpulkan bahwa aktivitas fisik berkorelasi dengan kualitas tidur pada ibu hamil.
\end{abstract}

Kata kunci: Aktivitas Fisik, Kualitas Tidur, Kehamilan

\begin{abstract}
Correlation of physical activities with sleep quality in pregnancy: a cross-sectional study. Poor sleep disorders can lead to pregnancy complications. Sleep disorders can be different for each pregnant woman depending on physical activity. The purpose of the study was to determine the correlation of physical activity with the quality of sleep in pregnant women. This type of research is a correlation with a cross sectional approach. The study population was 248 , with purposive sampling technique as many as 97 respondents. The research instrument used the International Physical Activity Questionnaire (IPAQ) and Pittsburgh Sleep Quality Index (PSQI) questionnaires. Data analysis using Chi Square. The results showed that $p$ value was $0.003(p<\alpha)$. It was concluded that physical activity correlated with the quality of sleep in pregnant woman.
\end{abstract}

Keywords: Physical Activity, Sleep Quality, Pregnancy 


\section{Pendahuluan}

Tidur merupakan suatu keadaan tidak sadar diri yang relatif, bukan karna hanya keadaan penuh ketenangan tanpa kegiatan, tetapi lebih kepada urutan siklus yang berulang (Uliyah \& Hidayat, 2008). Maslow (dalam Golmakani; 2015) menyatakan bahwa tidur merupakan salah satu kebutuhan dasar manusia. Gangguan tidur lebih sering terjadi pada wanita khususnya pada wanita yang sedang hamil.

Proses adaptasi terhadap adanya perubahan hormonal dan fisik selama kehamilan membuat ibu hamil sering mengalami gangguan pada saat tidur. Penelitian Klumpers et all (2015) menyebutkan kurang tidur dapat menimbulkan efek negatif seperti menurunnya kemampuan berpikir dan bekerja, membuat kesalahan dan sulit untuk mengingat sesuatu.

Tidur yang tidak adekuat dapat berdampak pada aspek fsiologis seperti penurunan aktivitas sehari-hari, rasa capai, lemah, proses penyembuhan lambat, daya tahan tubuh menurun dan ketidakstabilan tanda-tanda vital (Nurlela dkk, 2009; dalam Nuryanti, 2016). Pada ibu hamil efek yang terjadi bukan pada ibunya saja melainkan pada bayi yang dikandungnya. Kualitas dan kuantitas tidur yang buruk bisa mengganggu proses kekebalan tubuh ibu hamil. Selain itu juga berakibat bayi lahir dengan bobot rendah serta beberapa komplikasi lain (Prasadja, 2009; dalam Sukorini 2017).

National Sleep Foundatin (2007) dalam Sukorini (2017) menyebutkan perempuan hamil yang mengalami beberapa bentuk gangguan tidur mencapai $79 \%$. Sebanyak $72 \%$ dari ibu hamil akan mengalami frekwensi terbangun lebih sering pada malam hari. Aktivitas fisik adalah setiap gerakan tubuh yang meningkatkan pengeluaran tenaga dan energi atau pembakaran kalori (Kemenkes RI, 2015)

Aktivitas fisik dan olah raga pada ibu hamil harus dilakukan baik di tempat kerja, di rumah maupun di pelayanan kesehatan primer. American Heart Association (2009) merekomendasikan olah raga 30 hingga 60 menit dari aktivitas sedang hingga berat pada sebagian besar hari dalam seminggu, pada 50-75\% denyut jantung maksimal. Aktivitas tidak perlu terlalu berat untuk memberikan dampak terhadap kesehatan; melibatkan aktivitas sebagai bagian dari rutinitas kesehatan adalah yang terpenting.

Aktivitas menguntungkan, terutama bila dilakukan secara teratur (Lowdermilk., Perry., Cashion, 2013). Hasil penelitian Rashed (2016) terapi prilaku adalah salah satu metode non farmasi untuk mengelola masalah tidur pada ibu hamil. Ada berbagai tehnik terapi seperti relaksasi otot progresif otot, pijat, hipnotis, yoga, terapi musik, dan tehnik pernafasan. Sehingga dapat meningkatkan kesehatan mental dan fisik yang dapat membantu dalam banyak situasi dimana ibu hamil yang tegang, sakit dan cemas dapat menjadi lebih rileks dan meningkatkan kualitas tidur pada ibu hamil.

\section{Metode Penelitian}

Jenis penelitian yang digunakan yaitu korelasi dengan pendekatan cross sectional. Sumber data diperoleh dari ibu hamil yang berkunjung ke UPT Puskesmas Babakan Sari Kota Bandung saat melakukan kontrol kehamilan pada bulan Februari sampai dengan Agustus 2018 sebanyak 248 orang pada bulan Februari 2018. Teknik sampling menggunakan purposive dengan kriteria inklusi yaitu ibu dengan kehamilan tunggal dan tidak mengalami komplikasi atau penyakit penyerta yaitu sebanyak 97 responden.

Variabel penelitian terdiri dari aktivitas fisik dan kualitas tidur ibu hamil. Aktivitas fisik adalah kegiatan fisik ibu hamil yang dilakukan sehari-hari untuk membakar energi dalam satuan METs sesuai standar IPAQ. Alat ukur yang digunakan International Physical Activiti Questionnaire (IPAQ) dengan hasil ukur rendah (skor < 600 METs/menit/minggu), sedang (skor: 600$2999 \mathrm{METs} / \mathrm{menit} / \mathrm{minggu}$ ) dan tinggi (skor $\geq 3000 \mathrm{METs} /$ menit/minggu). Kualitas tidur adalah kepuasan tidur ibu hamil terhadap tidur yang terdiri dari kualitas subjektif, tidur laten, lama, efisiensi, gangguan, pemakaian 
obat, dan disfungsi siang hari. Alat ukur menggunakan Pittsburgh Sleep Quality Index (PSQI) dengan hasil ukur buruk (skor $\geq 5$ ) dan baik (skor < 5). Hipotesis penelitian yaitu ada hubungan aktivitas fisik dengan kualitas tidur.

Data dalam penelitian berupa data primer, data yang langsung diperoleh dari responden terhadap pertanyaan meliputi aktivitas fisik ibu hamil dan kualitas tidur ibu hamil. Pengolahan data meliputi editing, koding, entri, cleaning dan prosesing. Analisis data menggunakan distribusi frekuensi dan Chi Square.

\section{Hasil dan Pembahasan \\ Gambaran aktivitas fisik dan kualitas tidur}

Gambaran aktivitas fisik dan kualitas tidur ibu hamil disajikan dalam bentuk tabel 1 berikut.

Tabel 1

Distribusi Frekuensi Aktivitas Fisik dan Kualitas Tidur Responden (n=97)

\begin{tabular}{lcc}
\hline \multicolumn{1}{c}{ Variabel } & $\boldsymbol{f}$ & \% \\
\hline Aktivitas Fisik & & \\
Ringan & 17 & 17,5 \\
Sedang & 36 & 37,1 \\
Berat & 44 & 45,4 \\
Kualitas Tidur & & \\
Buruk & 63 & 64,9 \\
Baik & 34 & 35,1 \\
\hline
\end{tabular}

Tabel 1 menunjukkan bahwa ibu hamil umumnya melakukan aktivitas fisik berat sebanyak 44 responden $(45,4 \%)$ dan memiliki kualitas tidur buruk sebanyak 63 responden (64.9\%). Ibu hamil masih melakukan aktivitas sehari-hari seperti saat sebelum hamil, diantaranya mengerjakan

Selama masa kehamilan, ibu hamil dianjurkan untuk aktif bergerak, kecuali jika ada kontraindikasi yang menyababkan ibu hamil harus membatasai aktivitasnya. Aktivitas fisik yang dilakukan selama ibu hamil membuat ibu menyesuaikan tubuh dengan kondisi berat badan yang semakin bertambah, membantu mempermudah persalinan, menjaga kebugaran ibu, terhindar dari komplikasi kehamilan dan stres berkurang (Arum, 2016).

Aktivitas fisik berat merupakan kegiatan yang menggunakan banyak mengeluarkan energi sehingga nafas jauh lebih cepat dari biasanya dan dilakukan dalam waktu lebih dari 10 menit dengan jumlah METs $>3000$ METs/menit/minggu. Dalam penelitian ini banyak ibu hamil yang melakukan aktivitas naik turun tangga. pekerjaan rumah (mencuci pakaian, mengepel lantai, memasak, berbelanja), mengantar/menjemput anak sekolah, jalan kaki dengan naik turun tangga dengan membawa barang, dan masih aktif bekerja atau berjualan untuk memenuhi kebutuhan hidupnya.

Aktivitas berat dapat mempengaruhi naik turun tangga dapat meningkatkan kinerja jantung dan mempercepat aliran darah keseluruh tubuh sehinnga mengeluarkan banyak energi dan ketika tidur tubuh akan memerlukan energi pengganti agar tubuh bisa tetap bugar saat terbangun (Uliyah \& Hidayat, 2008).

Begitu juga dengan aktivitas sedang, pengeluaran energi yang dikeluarkan saat melakukan aktivitas yang menyebabkan bernafas agak lebih kuat dan dilakukan dalam waktu lebih dari 10 menit dengan jumlah METs 600-2999 METs/menit/minggu. Ibu hamil yang melakukan aktivitas sedang berupa mengerjakan pekerjaan rumah seperti mengepel lantai, memberesihkan rumah, dan menjemur pakaian. Tentunya aktivitas ini 
akan mengeluarkan cukup energi, memerlukan kekuatan otot, dan dapat meningkatkan kerja jantung untuk mensuplai kebutuhan energi keseluruh tubuh.

Sedangkan aktivitas berjalan kaki yang dilakukan dengan pengeluaran energi yang tidak begitu banyak dan dilakukan dalam waktu lebih dari 10 menit dengan jumlah METs < 600 METs/menit/minggu. Ibu hamil yang melakukan aktivitas jalan kaki baik sebagai olah raga untuk menjaga kesehatan maupun berjalan kaki dalam mengerjakan rutinitas sehari-hari.

Berjalan kaki dapat membuat baik untuk menjaga kesehatan jantung sirkulasi darah dalam tubuh sirkulasi darah dalam tubuh menjadi bagus, mencegah terjadinya varises, menguatkan otot dasar panggul, dapat mempercepat turunnya kepala bayi kedalam posisi optimal atau normal dan mempersiapkan mental menghadapi persalinan (Kusmiyati, 2008 dalam Taufik, 2014).

Kualitas tidur yang ditunjukkan dalam tabel 1 mengindikasikan bahwa banyak ibu hamil mengalami kualitas tidur buruk. Kualitas tidur yang buruk pada ibu hamil diakibatkan oleh waktu tidur ibu yang larut malam, tidak dapat memulai tidur dengan cepat, tidur yang terganggu akibat gangguan yang ibu rasakan saat tidur, dan terbangun terlalu dini sehingga ibu hamil tidak dapat mempertahankan kualitas dan kuantitas tidur.

Sukorini (2017) menyatakan sebagian besar ibu hamil memiliki kualitas tidur yang buruk. Dan diperkuat dalam penelitian penelitian Bat-Pitault Flora dkk (2015), yang melakukan penelitian tentang kualitas tidur pada ibu hamil dengan hasil $11 \%$ dari ibu hamil yang kurang tidur (kurang dari tujuh jam per malam) pada trimester pertama $20,6 \%$, pada trimester kedua 40,5\%, dan pada trimester ketiga $40,5 \%$.

Ibu hamil harus mempertimbangkan pola istirahat dan tidur yang mendukung kesehatan sendiri maupun kesehatan bayinya, kebiasaan tidur larut malam dan kegiatankegiatan malam hari harus dipertimbangkan dan kalau mungkin dikurangi hingga seminimal mungkin. Ibu hamil dianjurkan untuk merencanakan istirahat yang teratur seiring kemajuan kehamilannya.

Jadwal istirahat dan tidur perlu diperhatikan dengan baik, karena istirahat yang teratur dapat meningkatkan kesehatan jasmani dan rohani untuk kepentingan perkembangan dan pertumbuhan janin. Tidur pada malam hari selama kurang lebih 8 jam dan istirahat dalam keadaan rileks pada siang hari selama 1 jam (Musbikin, 2005; dalam Siallagan, 2010).

Kualitas tidur pada ibu hamil sebagian besar mengalami kualitas tidur buruk, kebanyakan ibu hamil sulit untuk memulai tidur dan sering terbangun pada malam hari diakibatkan gangguan yang terjadi yang membuat ibu terbangun dari tidurnya. Perlu adanya adaptasi agar kualitas tidur ibu tetap terjaga dan ibu tetap bugar karna kebutuhan tidur ibu terpenuhi.

\section{Hubungan Aktivitas Fisik Dengan Kualitas Tidur Pada Ibu Hamil}

Hasil analisis mengenai hubungan aktivitas fisik dengan kualitas tidur pada ibu hamil ditampilkan pada tabel 2 berikut.

Tabel 2

Korelasi aktivitas fisik dengan kualitas tidur ibu hamil $(n=97)$

\begin{tabular}{lccccccc}
\hline \multirow{2}{*}{ Aktivitas fisik } & \multicolumn{4}{c}{ Kualitas tidur } & \multicolumn{2}{c}{ Total } & \multirow{2}{*}{ P value } \\
\cline { 2 - 7 } & \multicolumn{3}{c}{ Buruk } & \multicolumn{2}{c}{ Baik } & & \\
\cline { 2 - 7 } & $\mathbf{f}$ & $\mathbf{\%}$ & $\mathbf{f}$ & $\mathbf{\%}$ & $\mathbf{f}$ & $\mathbf{\%}$ & \\
\hline Ringan & 15 & 15,4 & 2 & 2,1 & 17 & 17,5 & 0,003 \\
\hline Sedang & 5 & 5,2 & 31 & 32,0 & 36 & 37,1 & \\
\hline Berat & 43 & 44,3 & 1 & 1,0 & 44 & 45,4 & \\
\hline
\end{tabular}


Berdasarkan tabel 2 didapatkan hasil bahwa aktivitas fisik berhubungan dengan kualitas tidur pada ibu hamil, dari hasil penelitian 97 responden, terdapat 17 responden $(17,5 \%)$ melakukan aktivitas fisik ringan mengalami 15 responden $(15,4 \%)$ buruk dan 2 responden $(2,1 \%)$ baik, 36 responden $(37,1 \%)$ melakukan aktivitas fisik sedang, dengan kualitas tidur 5 responden $(5,2 \%)$ mengalami buruk dan 31 rerponden atau $(32,0 \%)$ mengalami kualitas tidur baik, dan 44 responden atau $(45,4 \%)$ yang mengalami aktivitas berat dengan kualitas tidur 43 responden $(44,3 \%)$ buruk dan 1 responden $(1,0 \%)$ mengalami kualitas tidur baik. Berdasarkan hasil penelitian dalam penelitian ini di dapatkan $\rho$-value $=0.003(\rho$ value $<0,05$ ) yang berarti terdapat hubungan yang signifikan antara aktivitas fisik dengan kualitas tidur pada ibu hamil.

Hasil analisis data yang menggunakan uji chi-square, didapatkan hasil bahwa nilai p-value $=0,003$ lebih kecil dari nilai taraf signifikasi sebesar $0,05(p<\alpha)$, sehingga $\mathrm{Ha}$ diterima yang artinya ada hubungan yang signifikan antara aktivitas fisik dengan kualitas tidur pada ibu hamil di wilayah kerja UPT Puskesmas Babakan Sari Kota Bandung.

Berdasarkan hasil penelitian aktivitas fisik dengan kualitas tidur pada ibu hamil di wilayah kerja UPT Puskesmas Babakan sari, peneliti menganalisis bahwa ibu hamil yang melakukan aktivitas ringan dan berat mengalami kualitas tidur yang buruk, ibu hamil sulit memulai tidur setelah berbaring di tempat memerlukan waktu yang cukup panjang untuk memulai tidur dan sering terbangun lebih awal sehingga secara kualitas dan kuantitas tidur tidak terpenuhi, ditambah lagi dengan gangguan yang terjadi setelah tidur yang membuat tidur ibu tidak nyaman dan sering terganggu.

Gangguan tidur dapat berupa kram saat tidur, sulit bernafas, terbangun untuk kekamar mandi, kepanasan atau kedinginan yang membuat tidur ibu terganggu. Hal ini sejalan dengan penelian Puspita (2014), aktivitas fisik ringan mempengaruhi kualitas tidur menjadi buruk dikarnakan kurangnya aktivitas pada ibu hamil mengakibatkan ibu tidak dapat rileks sehingga sulit memulai tidur. Sedangkan aktivitas yang tinggi dapat memerlukan lebih banyak tidur untuk menjaga keseimbangan energi yang telah dikeluarkan. Hal tersebut terlihat pada seseorang yang telah melakukan aktivitas dan mencapai kelelahan. Maka, orang tersebut akan lebih cepat untuk dapat tidur karena tahap tidur gelombang lambatnya diperpendek, saat kelelahan akan terjadi gangguan kenyamanan fisik sehingga tidur akan terganggu. Aktivitas yang tinggi membutuhkan lebih banyak tidur untuk menjaga keseimbangan energinya yang telah dikeluarkan. Kondisi tubuh yang lelah dapat mempengaruhi gaya tidur seseorang. Semakin lelah seseorang, semakin pendek siklus tidur REM yang dilaluinya. Setelah beristirahat biasanya siklus REM akan kembali memanjang (Uliah dan Hidayah, 2008).

Aktivitas sedang cenderung memiliki kualitas tidur yang baik hal ini desebabkan karena aktivitas sedang yang dilakukan oleh ibu hamil dapat membantu jantung berkerja dengan baik dan peredaran darah menjadi lancar dengan pengeluaran energi yang seimbang dan mengurangi pengeluaran hormon sehingga ibu hamil lebih rileks dan dapat memulai tidur dengan cepat, aktivitas fisik secara teratur selama kehamilan memiliki keuntungan untuk mobilitas, kebugaran, dan kualitas tidur (Kolu, 2014) terhindar dari keluhan tidur apnea obstruktif (Rafknowledge, 2004 dalam Nuryati, 2016).

Peneliti berpendapat bahwa aktivitas fisik sangat mempengaruhi kualitas tidur pada ibu hamil. Jadi, secara teori aktivitas fisik berpengaruh pada kualitas tidur ibu hamil. Sehingga peneliti menganalisis adanya kecenderungan dengan aktivitas yang dilakukan berat dan rendah membuat kualitas tidur ibu menjadi buruk sedangkan aktivitas yang sedang dapat memberikan kualitas tidur yang baik.

Karena aktivitas fisik berat yang dilakukan ibu hamil dapat membuat ibu kelelahan dan memerlukan waktu tidur yang cukup lama untuk menggantikan energi yang 
dikeluarkan, kelelahan dapat membuat gelombang REM tidur ibu membuat kualitas dan kuantitas tidur ibu tidak terpenuhi. Sedangkan dengan aktivitas fisik ringan membuat ibu tidak riles dan sulit untuk memulai tidur.

Berbeda halnya dengan aktivitas fisik sedang yang dapat menjaga kualitas tidur ibu lebih baik, kerja jantung yang baik stelah malakukan aktivitas sedang membuat sirkulasi darah keseluruh tubuh ibu dan janin baik, ibu akan lebih rileks untuk memulai tidur dan gelombang REM yang saat tidur terjaga sehingga dapat mampu mengembalikan energi kembali yang telah ibu keluarkan setelah beraktivitas.

\section{Simpulan}

Aktivitas fisik ibu hamil umumnya tidak berbeda dengan aktivitas sebelum hamil. Sebelum hamil aktivitas fisik yang biasa dilakukan tidak mengganggu terhadap kualitas tidur. Adanya perubahan fisiologis kehamilan memperberat sistem tubuh yang dapat mempengaruhi kualitas tidur.

Semakin tinggi aktivitas fisik yang dilakukan semakin buruk pula kualitas tidur ibu hamil. Hal ini disebabkan meningkatnya metabolisme tubuh ibu hamil.

\section{Daftar Pustaka}

Golmakani, N., Seyed Ahmadi Nejad, F. S., Shakeri, M. T., \& Asghari Pour, N. Comparing the Effects of Progressive Muscle Relaxation and Guided Imagery on sleep quality in primigravida women referring to Mashhad health care centers-1393. Journal of Midwifery and Reproductive Health, 3(2), 335342. 2015. 1(1), 1-12. dikutip 27 Februari 2018. Tersedia di URL: http://jmrh.mums.ac.ir/article_395 1_548.html.

IPAQ RESEARCH COMMITTEE, et al. Guidelines for data processing and analysis of the International Physical Activity Questionnaire (IPAQ)-short and long forms. http://www. ipaq. ki. se/scoring. pdf, 2005. dikutip 7 Maret 2018. Tersedia di URL: https://ci.nii.ac.jp/naid/100303185 51/

Kementrian Kesehatan RI. 2015. Pembinaan Kesehatan Olahraga di Indonesia. Jakarta: Pusat Data dan Informasi Kementrian Kesehatan RI.

Klumpers, U. M. H., Veltman, D. J., van Tol, M. J., Kloet, R. W., Boellaard, R., \& Lammertsma, A. A. Neurophysiological Effects of Sleep Depriva-tion in Healthy Adults, a Pilot Study. PLoS ONE, 10(1), e0116906. 2017. 1(1), 1-12. dikutip 01 Maret 2018. Tersedia di URL:

http://journals.plos.org/plosone/arti cel

Lowdermilk., D., L., Perry., S., E., Cashion., K. 2013. Keperawatan Maternitas: Edisi 8, Buku 1. Indonesia: Salemba Medika.

Nuryanti, E. A. Analisis Determinan Kualitas Tidur pada Pekerja Shift Wanita di PT. Sandratex Tahun 2016 (Bachelor's thesis, FKIK UIN Jakarta). 2016. . 1(1), 1-12. dikutip 27 Februari 2018. Tersedia di URL:

http://repository.uinjkt.ac.id/dspac e/handle/123456789/34272

Puspita, E. (2014). Aktivitas Fisik Dan Gaya Hidup Dengan Kualitas Tidur Pada Ibu Hamil Trimester Iii Di Bpm Ny."M"'Studi Di Desa Banjar Tanggul Pungging Mojokerto). Kti D3 Kebidanan. Dikutip 17 Juni 2018. Tersedia di URL: http://repository.poltekkesmajapah it.ac.id

Rashed, A. B. A. A., Khalil, A. K., Mohamed, H., \& Shereda, A. Effect of Non-Pharmacological Interventions on Sleep Quality during Pregnancy among Primigravida. 1(1), 1-12. 2016. dikutip 28 Februari 2018. Tersedia di URL: https://scholar.google.co.id 
Sukorini, M. U. Hubungan Gangguan Kenyamanan Fisik Dan Penyakit Dengan Kualitas Tidur Ibu Hamil Trimester III. The Indonesian Journal of Public Health. 2017. 1(1), 1-12. dikutip 27 Februari 2018. Tersedia di URL: https://ejournal.unair.ac.id/IJPH/article/vie w/7108

Taufik, M., Chakim, N., \& Fajriyah, N. N. (2014). Tekanan Darah Ibu Hamil
Primigavida Sebelum dan Sesudah melakukan Olahraga Jalan Kaki Selama Sepuluh Menit. Jurnal Ilmiah Kesehatan (JIK), 6(1), dikutip 27 Juni 2018. Tersedia di URL: http://www.journal.stikesmuh Uliyah., M., \& Hidayat., A., A., A. 2008. Keterampilan Dasar. Praktik Klinik Untuk Kebidanan. Jakarta: Salemba Medika. 